\title{
A Modified Model for Deflection Calculation of Reinforced Concrete Beam with Deformed GFRP Rebar
}

\author{
Minkwan Ju, ${ }^{1}$ Hongseob Oh, ${ }^{2}$ Junhyun Lim, ${ }^{3}$ and Jongsung Sim ${ }^{4}$ \\ ${ }^{1}$ Department of Civil Engineering, Kangwon National University, Gangwon-do 25913, Republic of Korea \\ ${ }^{2}$ Department of Civil Engineering, Gyeongnam National University of Science and Technology, 150 Chilam-dong, \\ Jinju, Gyeongsangnam-do 52725, Republic of Korea \\ ${ }^{3}$ Sambo Engineering, 30 Bang i-dong, Wiryeseong-daero 16-gil, Songpa-gu, Seoul 05640, Republic of Korea \\ ${ }^{4}$ Department of Civil and Environmental Engineering, Hanyang University, Ansan 15588, Republic of Korea
}

Correspondence should be addressed to Hongseob Oh; opera69@chol.com

Received 27 March 2016; Revised 9 July 2016; Accepted 19 July 2016

Academic Editor: Ulrich Maschke

Copyright (C) 2016 Minkwan Ju et al. This is an open access article distributed under the Creative Commons Attribution License, which permits unrestricted use, distribution, and reproduction in any medium, provided the original work is properly cited.

\begin{abstract}
The authors carried out experimental and analytical research to evaluate the flexural capacity and the moment-deflection relationship of concrete beams reinforced with GFRP bars. The proposed model to predict the effective moment of inertia for R/C beam with GFRP bars was developed empirically, based on Branson's equation to have better accuracy and a familiar approach to a structural engineer. For better prediction of the moment-deflection relationship until the ultimate strength is reached, a nonlinear parameter $(k)$ was also considered. This parameter was introduced to reduce the effect of the cracked moment of inertia for the reinforced concrete member, including a lower reinforcement ratio and modulus of elasticity of the GFRP bar. In a comparative study using six equations suggested by others, the proposed model showed better agreement with the experimental test results. It was confirmed that the empirical modification based on Branson's equation was valid for predicting the effective moment of inertia of R/C beams with GFRP bar in this study. To evaluate the generality of the proposed model, a comparative study using previous test results from the literature and the results from this study was carried out. It was found that the proposed model had better accuracy and was a familiar approach to structural engineers to predict and evaluate the deflection behavior.
\end{abstract}

\section{Introduction}

Service life of reinforced concrete (RC) structures can be decreased by a number of factors including harsh environmental conditions and unexpected excessive external loads. One of the main factors contributing to degradation of structural condition is the corrosion of steel reinforcement. Hence, using a noncorrosive reinforcement can be an effective solution to increase the service life of RC structures. In many regions, fiber-reinforced polymer (FRP) bars have been of considerable interest to civil (structures) and structural engineers for strengthening and reinforcing concrete as a substitute for steel bars. Their high strength-to-weight ratio, corrosion-free properties, and ease of handling during construction are considered advantages for application in civil structures. Much structural research using FRP bars has been performed in field applications and there are now guidelines for the design and construction of concrete reinforced using FRP bars, such as the AASHTO LRFD Bridge Design Specification, ACI 440 guidelines, and the Canadian Design Code [1-3].

The flexural capacity of reinforced concrete members with GFRP bar has been an issue in structural design due to the relatively low modulus of elasticity, which causes a larger deflection and crack width. Thus, the flexural behavior of reinforced concrete members with GFRP bar should be investigated further with respect to serviceability. The prediction of deflection behavior is one of the most important criteria in evaluating and ensuring the serviceability of concrete member. ACI 318-14 [4] uses an equation for the moment of inertia based on Branson's equation [5] to calculate the deflection of reinforced concrete beams. Recently, ACI 440.1R-15 [2] recommended a new model for the moment of inertia for reinforced concrete members with GFRP bar that was not 
based on Branson's equation in contrast with ACI 440.1R06 [6]. The Branson-based equation has long been familiar to most structural engineers in designing flexural concrete members. For Reinforced concrete members with GFRP bar, Branson's equation had been modified to predict the deflection as accurately as possible. The significant modifications were to correct the power of $m$ and to add a parameter.

In this study, we suggest a modified effective moment of inertia and carried out a comparative study regarding the deflection behavior of R/C beams with GFRP bar with experimental tests. For the comparative study, six equations including some from individual research were considered. The proposed model was developed based on Branson's equation to provide a familiar approach to calculate the moment of inertia for R/C beams with GFRP bar. This model was empirically modified according to the test results of the six test specimens with variables of the reinforcement ratio. For better prediction of deflection until ultimate strength was reached, an empirical nonlinear parameter was introduced to reduce the effect of the cracked moment of inertia. Among the equations, the degree of accuracy in the prediction of deflection behavior for the new moment of inertia suggested in this study was analyzed and predictability was discussed.

\section{Existing and Proposed Equations for the Moment of Inertia for FRP Bar-Reinforced Concrete Flexural Members}

Branson's equation generally underestimates the deflection of FRP-reinforced concrete beams. Benmokrane et al. [7] modified the equation to make it more suitable for evaluating the deflection of FRP-reinforced concrete beams based on experimental data. The equation is as follows:

$$
I_{e}=\left(\frac{M_{\mathrm{cr}}}{M_{a}}\right)^{3} \frac{I_{g}}{\beta}+\alpha\left[1-\left(\frac{M_{\mathrm{cr}}}{M_{a}}\right)^{3}\right] I_{\mathrm{cr}} \leq I_{g},
$$

where $I_{g}$ is the gross moment of inertia $\left(\mathrm{mm}^{4}\right), I_{\mathrm{cr}}$ is the moment of inertia of transformed cracked section $\left(\mathrm{mm}^{4}\right)$, $M_{\mathrm{cr}}$ is the cracking moment $(\mathrm{N} \cdot \mathrm{m})$, and $M_{a}$ is the maximum service load moment in member $(\mathrm{N} \cdot \mathrm{m})$.

The noticeable difference lies in the modification of $\alpha$ and $\beta . \alpha$ reflects the reduced composite action between the concrete and FRP bars. However, $\beta$ has no physical significance because there was no justification for reducing $I_{g} . \alpha$ and $\beta$ were 0.84 and 7 , respectively.

ACI 440.1R-06 [6] recommended an equation for the effective moment of inertia based on Branson's model. There was an additional factor for considering the reduced tension stiffening of FRP-reinforced concrete members. This model has been commonly used to calculate the moment of inertia of FRP-reinforced concrete members, so that the deflection of the cracked section can be calculated:

$$
I_{e}=\left(\frac{M_{\mathrm{cr}}}{M_{a}}\right)^{3} \beta_{d} I_{g}+\left[1-\left(\frac{M_{\mathrm{cr}}}{M_{a}}\right)^{3}\right] I_{\mathrm{cr}} \leq I_{g},
$$

where $\beta_{d}$ is the reduction factor related to the reduced tension stiffening exhibited by $\mathrm{R} / \mathrm{C}$ member with FRP bar $\left(=(1 / 5)\left(\rho_{f} / \rho_{f b}\right) \leq 1.0\right), \rho_{f}$ is the reinforcement ratio of GFRP bar, and $\rho_{f b}$ is the balanced reinforcement ratio of GFRP bar.

Toutanji and Saafi [9] empirically suggested an equation for the effective moment of inertia for reinforced concrete beam with GFRP bar. Their equation focused on the modification factor of the power of $m$ in (1). The factor was based on applying the modulus ratio to the reinforcement ratio of the FRP bar. By only modifying the power of $m$, the conventional form of the equation, which is familiar to structural engineers, was maintained. The equation predicted the deflection of the tested R/C beams with GFRP well. Consider

$$
I_{e}=\left(\frac{M_{\mathrm{cr}}}{M_{a}}\right)^{m} I_{g}+\left[1-\left(\frac{M_{\mathrm{cr}}}{M_{a}}\right)^{m}\right] I_{\mathrm{cr}} \leq I_{g}
$$

where $m=6-10 \rho_{\mathrm{F}} E_{\mathrm{F}} / E_{s}$.

For the Canadian Code for reinforced concrete members with FRP bar, CAN/CSA S806-12 [3] suggested the following equation (see (4)) for calculating the deflection. The equation was based on the conventional equation for calculating deflection under four-point loading. It uses the cracked moment of inertia, while ACI 440.1R-15 [2] uses the effective moment of inertia. However, additional equation terms referring to shear span, span length, and uncracked length in half of the beam were included. This equation requires a calculation-intensive process subject to human error; thus, the code also provides closed-form equations for common loading and support conditions. Hence,

$$
\Delta=\frac{P a}{48 E_{c} I_{\mathrm{cr}}}\left(3\left(\frac{a}{L}\right)-4\left(\frac{a}{L}\right)^{3}-8 \eta\left(\frac{L_{g}}{L}\right)^{3}\right),
$$

where $a$ is the shear span ( $\mathrm{mm}), P$ is the total applied load $(\mathrm{N}), L$ is the span length $(\mathrm{mm}), L_{g}$ is the uncracked length in half of the beam $(\mathrm{mm})\left(=a\left(M_{\mathrm{cr}} / M_{a}\right)\right)$, and $E_{c}$ is the modulus of elasticity of concrete $(\mathrm{MPa}), \eta=\left(1-I_{\mathrm{cr}} / I_{g}\right)$.

Recently, the other semiempirical model was suggested by modifying Branson's equation according to experimental results and a genetic algorithm approach [10]. For better prediction, some of the factors were developed empirically. The model, which has two multiplying factors and an exponential factor $m$, was analyzed using experimental data for 55 FRP-reinforced concrete beams for the load-deflection relationship. The effects of the elastic modulus of FRP bars, reinforcement ratio, and level of loading on the power of $m$ in Branson's equation are taken into account in (5) as follows:

$$
I_{e}=0.13\left(\frac{M_{\mathrm{cr}}}{M_{a}}\right)^{m} I_{g}+0.89\left[1-\left(\frac{M_{\mathrm{cr}}}{M_{a}}\right)^{m}\right] I_{\mathrm{cr}} \leq I_{g},
$$

where $m=-0.24\left(\rho_{f} / \rho_{f b}\right)+5.35\left(M_{\mathrm{cr}} / M_{a}\right)+2.28\left(E_{f} / E_{s}\right), E_{f}$ is the modulus of elasticity of FRP bar $(\mathrm{MPa})$, and $E_{s}$ is the modulus of elasticity of steel bar $(\mathrm{MPa})$.

ACI 440.1R-15 [2] suggested an equation for calculating the effective moment of inertia for reinforced concrete beams with FRP bar. This equation is based on Bischoff's proposed approach, which represents a weighted average of flexibility 


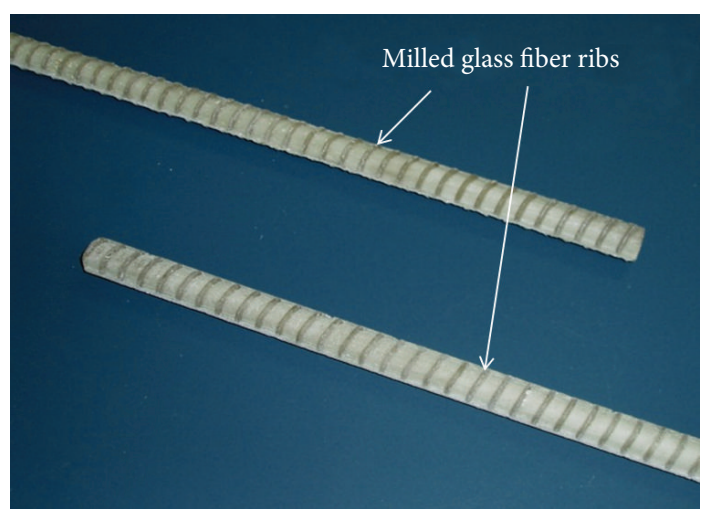

(a) Detailing of GFRP reinforcing bar
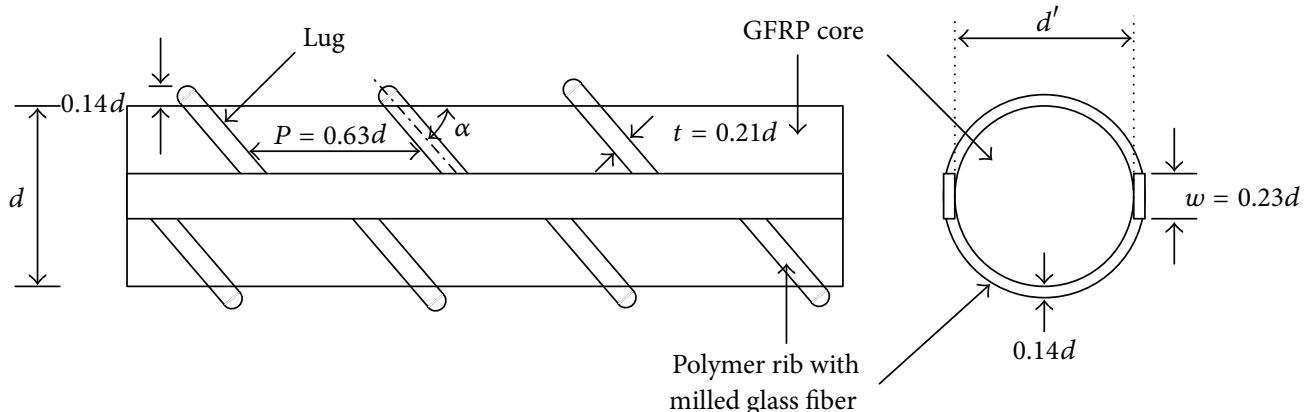

$P=$ Lug pitch $\alpha=80^{\circ}$

(b) Surface pattern of GFRP reinforcing bar

FIGURE 1: GFRP reinforcing bar used in this study [8].

$\left(1 / E_{c} I\right)$, as shown in (6). It was reported that the equation works equally well for both steel- and GFRP-reinforced concrete members with no empirical parameter [11]. Therefore,

$$
I_{e}=\frac{I_{\mathrm{cr}}}{1-\gamma\left(M_{\mathrm{cr}} / M_{a}\right)^{2}\left[1-I_{\mathrm{cr}} / I_{g}\right]} \leq I_{g},
$$

where $\gamma$ is the parameter to account for the variation in stiffness along the length of the member for four-point bending. Hence,

$$
\gamma=\frac{3(a / L)-16\left(M_{\mathrm{cr}} / M_{a}\right)(a / L)^{2}+12(a / L)^{3}}{3(a / L)-4(a / L)^{3}} .
$$

Intelligent sensing for innovative structures [12] recommended following (8) of the effective moment of inertia for FRP bar-reinforced concrete beams. This equation added additional corrective terms in a modified Branson equation with more experimental data. The notations are introduced above in equations from (1) to (6). Here, we have

$$
I_{e}=\frac{I_{g} I_{\mathrm{cr}}}{I_{\mathrm{cr}}+\left(1-0.5\left(M_{\mathrm{cr}} / M_{a}\right)\right)^{2}\left(I_{g}-I_{\mathrm{cr}}\right)} .
$$

\section{Experimental Tests}

3.1. Description of the GFRP Bar. The GFRP reinforcing bar used in this study is developed reinforcement having a similar outer shape to conventional steel bars. It consists of continuous longitudinal glass fibers with a $67 \%$ volume fraction in a thermosetting epoxy. A typical pultrusion process was adopted. To enhance the shear resistance under bonding, milled glass fiber ribs were formulated on the GFRP core. To form the fiber ribs, a steel mold was used in the curing process. The rib section of the GFRP bar was manufactured by mixing milled glass fiber and epoxy at a ratio of $1: 1$ by weight, and it was cured for $15 \mathrm{~min}$ at a temperature above $160^{\circ} \mathrm{C}$. Details of the external shape of the GFRP bar with fiber ribs were provided by Ju and Oh [8] (Figure 1(b)).

The GFRP bar used for the tensile area had a nominal diameter of $9.53 \mathrm{~mm}$. Tensile tests were conducted with eight test specimens according to ACI 440.3R-04 [13]. The tensile specimens were loaded through thick plates at the anchored ends. A universal testing machine (UTM) with a capacity of $2,000 \mathrm{kN}$ was used and the loading rate was $17.8 \mathrm{kN} / \mathrm{min}$. Among the test specimens, the maximum tensile strength was found to be $871.4 \mathrm{MPa}$. Table 1 summarizes the tensile strength of the GFRP bar. The guaranteed tensile strength with standard deviation was calculated to be $616.0 \mathrm{MPa}$. The designed tensile strength was calculated by multiplying the 
TABLE 1: Mechanical properties of the GFRP bar used in this study.

\begin{tabular}{lccccc}
\hline $\begin{array}{l}\text { Average tensile } \\
\text { strength }(\mathrm{MPa})\end{array}$ & $\begin{array}{c}\text { Guaranteed tensile } \\
\text { strength }(\mathrm{MPa})\end{array}$ & $\begin{array}{c}\text { Guaranteed } \\
\text { ultimate strain }(\%)\end{array}$ & $\begin{array}{c}\text { Design tensile } \\
\text { strength }(\mathrm{MPa})\end{array}$ & $\begin{array}{c}\text { Design rupture } \\
\text { strain }(\%)\end{array}$ & $\begin{array}{c}\text { Modulus of } \\
\text { elasticity }(\mathrm{GPa})\end{array}$ \\
\hline $841.0 \pm 23.6$ & $770.2^{*}$ & $1.65^{*}$ & $539.1^{* *}$ & $1.16^{* *}$ & 42.1 \\
\hline
\end{tabular}

${ }^{*}$ ACI Committee 440 [2]: average $-3 \times$ standard deviation.

${ }^{* *}$ Environmental reduction factor $\left(C_{E}\right)$ is applied with 0.7 , exposed to earth and weather.
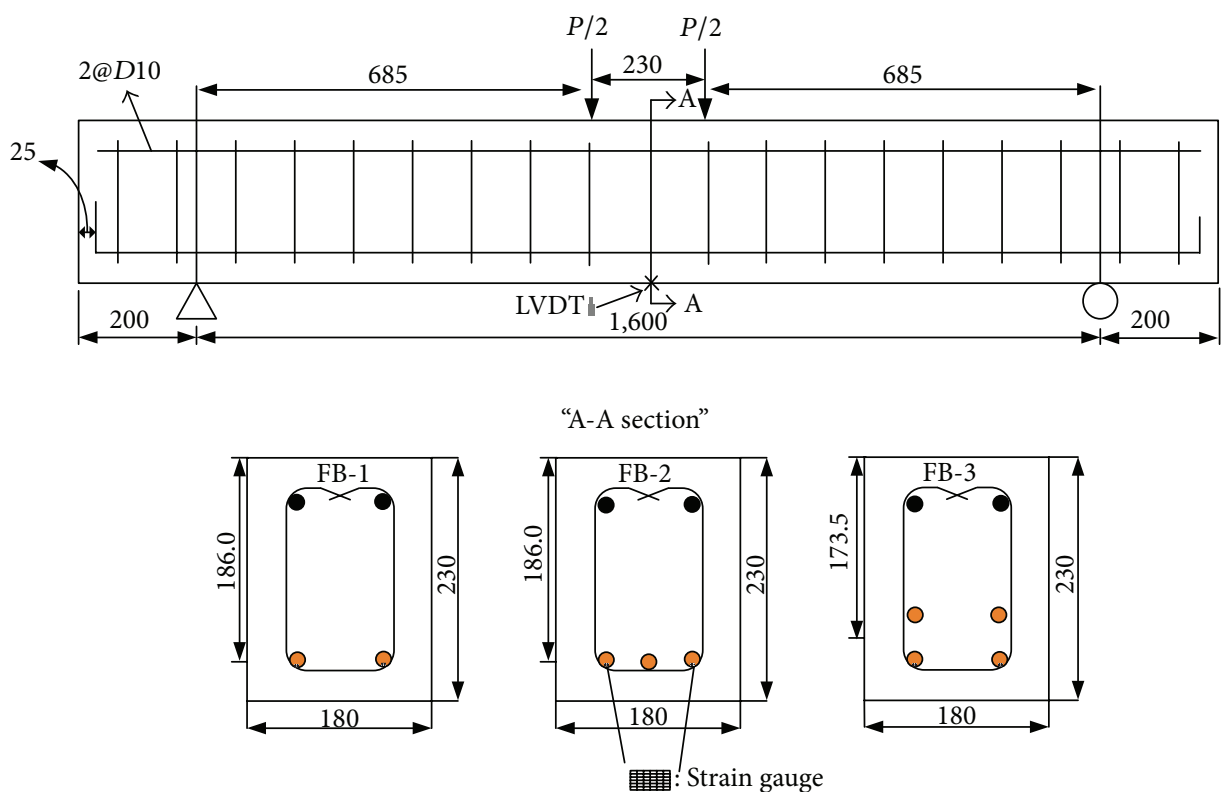

FIgURE 2: Test setup and measurement detail (in $\mathrm{mm}$ ).

environmental reduction factor (0.7, for external exposure) in compliance with ACI 440.1R-15 [2], resulting in 539.1 MPa. The modulus of elasticity was found to be $42.9 \mathrm{GPa}$, within the general range of the modulus of elasticity for GFRP bars.

3.2. Test Setup. For a GFRP bar, the conventional ductility design used for steel bars is not appropriate because of the absence of a yield point. Three types of $\mathrm{R} / \mathrm{C}$ beams with GFRP bar were designed according to ACI 440.1R15 [2]: FRP rupture (FB-1), balanced (FB-2), and concrete crushing (FB-3) failure. Three different amounts of longitudinal reinforcement GFRP bar were used: 2D10 for FB-2, 3D10 for FB-3, and 4D10 for FB-4. D indicates the nominal diameter of the GFRP bar. For the balanced FB-2, it may be regarded as FRP rupture failure with concrete crushing. Each specimen consisted of two identical beams. The flexural test was conducted by four-point bending. Figure 2 shows the test setup and measurement details. The dimensions of the test beams were as follows: $180 \mathrm{~mm}$ wide, $230 \mathrm{~mm}$ deep, and 2,000 $\mathrm{mm}$ long. The pure span was $1,600 \mathrm{~mm}$. The shear span of $a / d$, which can determine the governed behavior of the flexural beam, was calculated to be between 3.7 and 3.9; thus, the beam was regarded as being subjected to flexural behavior. To monitor the structural behavior of the beam, linear variable differential transformers (LVDTs) were installed at the bottom surface of the concrete in the midsection. Two electric resistance strain gauges were attached to the surface of the centered GFRP bar for FB-2 and the outer GFRP bar for FB-1 and FB-3 at the midsection. The two loads were automatically applied to the beam at a rate of $2 \mathrm{kN}$ per minute using MTS loading machine. All data (forces, strains, and deflections) were collected by an automated data acquisition system. For crack width, a crack measure was used and crack width was investigated visually at the individual loading step. For the concrete, the average 28-day compressive strength was $27.0 \mathrm{MPa}$ and the flexural tensile strength of the concrete was approximately $2.4 \mathrm{MPa}$.

3.3. Flexural Test Results and Discussion. Flexural failure and crack patterns are shown in Figure 3. The specimens failed in a typical flexural failure manner. FB-1 showed a cracking load of $12.0 \mathrm{kN}$. The failure was governed by rupture of the GFRP bars. The maximum crack width at the midsection was investigated visually and found to be $0.9 \mathrm{~mm}$. The FB2 specimen initiatally failed by crushing of the concrete and then finally collapsed due to rupture of the GFRP bar. Consequently, the failures showed compression tension failure with rupture of the GFRP bar and the maximum crack width was $0.7 \mathrm{~mm}$. In the case of the FB-3 specimen, it showed conventional concrete crushing failure without rupture of the GFRP bar. The maximum crack width was measured as $0.4 \mathrm{~mm}$ at the midsection. For flexural capacity, it was found that the designed failure modes represented the experimental modes of failure and the crack width was 


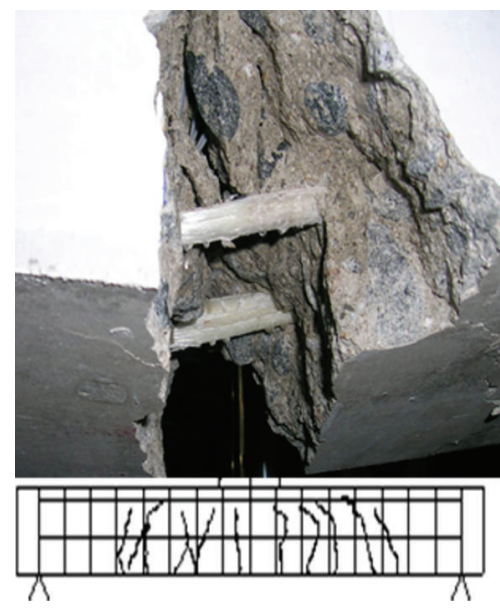

(a) FB-1

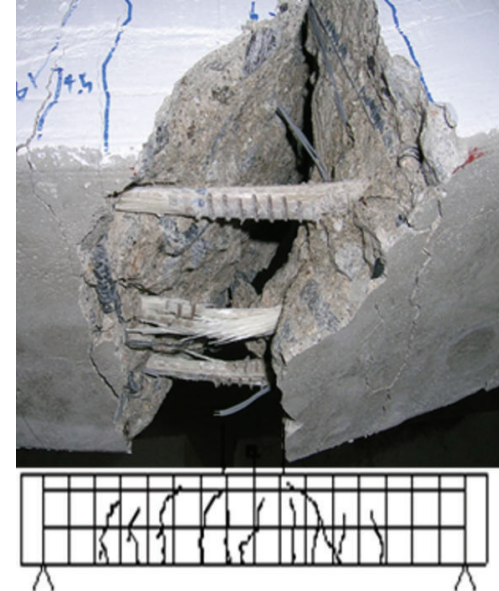

(b) FB-2

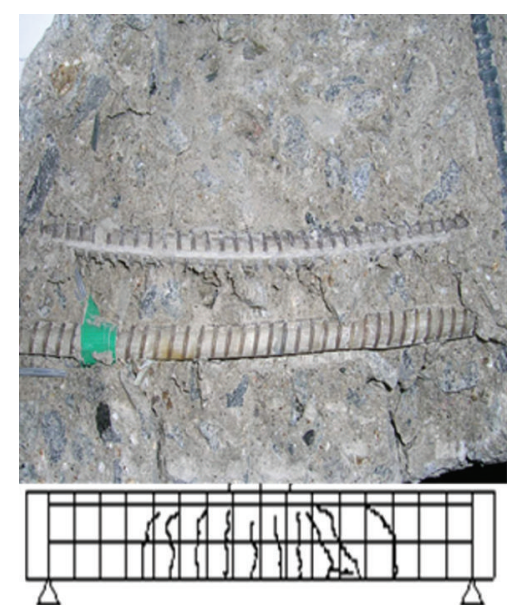

(c) FB-3

FIGURE 3: Flexural failure and crack patterns of FB-1, FB-2, and FB-3.

TABLE 2: Result of experimental test of GFRP bar reinforced concrete beams.

\begin{tabular}{|c|c|c|c|c|c|c|c|}
\hline Specimen & $\begin{array}{l}\text { Reinforcement } \\
\text { ratio (balanced) }\end{array}$ & $\begin{array}{c}\text { Average load at } \\
\text { initial cracking } \\
\qquad(\mathrm{kN})\end{array}$ & $\begin{array}{l}\text { Average load at } \\
\text { ultimate state } \\
(\mathrm{kN})\end{array}$ & $\begin{array}{c}\text { Average } \\
\text { deflection at } \\
\text { ultimate state } \\
(\mathrm{mm})\end{array}$ & $\begin{array}{l}\text { Nominal } \\
\text { moment (exp.) } \\
(\mathrm{kN} \cdot \mathrm{m})\end{array}$ & $\begin{array}{c}\text { Nominal } \\
\text { moment (cal.) } \\
(\mathrm{kN} \cdot \mathrm{m})\end{array}$ & Mode of failure \\
\hline FB-1 & $\begin{array}{l}0.00427 \\
(0.0069)\end{array}$ & 12.0 & 54.4 & 34.4 & 18.6 & 13.6 & FRP rupture \\
\hline FB-2 & $\begin{array}{c}0.0064 \\
(0.0069)\end{array}$ & 10.0 & 64.8 & 39.1 & 22.2 & 19.9 & $\begin{array}{l}\text { Compression } \\
\text { tension }\end{array}$ \\
\hline FB-3 & $\begin{array}{c}0.00903 \\
(0.0069)\end{array}$ & 12.0 & 74.0 & 26.6 & 25.4 & 21.0 & $\begin{array}{l}\text { Concrete } \\
\text { crushing }\end{array}$ \\
\hline
\end{tabular}

reduced as the reinforcement ratio was increased. Cracking in the flexural zone predominantly consisted of vertical cracks perpendicular to the direction of maximum principle stress induced by the pure flexural moment. Cracking was initiated at the middle of the span and then propagated toward the supports.

Eventually, shear stress became more important and induced inclined cracks. When reaching ultimate strength, flexural cracks propagated towards the vicinity of the load points on the compressive face of the beams. All test beams showed significant flexural cracking before inclined cracks joined flexural cracks. For an analytical approach regarding the nominal flexural moment, the equation from ACI 440.1R15 [2] was used with a varying reinforcement ratio. When $\rho_{f}<\rho_{f b}$, the controlling limit state is rupture of the FRP bar and the nominal flexural strength can be computed. Based on the equilibrium of forces and strain compatibility, (10) can be derived. Otherwise, when $\rho_{f}>\rho_{f b}$, the design tensile strength $\left(f_{f u}\right)$ in (10) is changed to the stress in FRP $\left(f_{f}\right)$ in tension (see $\left.(9)\right)$. Table 2 shows the experimentally and analytically obtained flexural moment strengths of R/C beams with GFRP bar. The theoretical moment strength was evaluated and was about $20 \%$ lower than that of the moment strength in the experimental test. This may be due to variation resulting from the small number of test specimens. However, the calculated moment strength could well represent the structural capacity as a conservative prediction. For structural stiffness, defined by dividing the average load by the average deflection at ultimate strength, FB-1, FB-2, and FB3 showed values of $1.58,1.65$, and 2.78 , respectively. It was found that the structural stiffness increased according to the increase in the reinforcement ratio of the GFRP bar:

$$
\begin{aligned}
f_{f} & =\left(\sqrt{\frac{\left(E_{f} \varepsilon_{c u}\right)^{2}}{4}+\frac{0.85 \beta_{1} f_{c}^{\prime}}{\rho_{f}} E_{f} \varepsilon_{c u}}-0.5 E_{f} \varepsilon_{c u}\right) \\
& \leq f_{f u}, \\
M_{n} & =A_{f} f_{f u}\left(d-\frac{a}{2}\right),
\end{aligned}
$$

where $M_{n}$ is the nominal flexural strength $(\mathrm{kN} \cdot \mathrm{m}), a$ is the depth of equivalent rectangular stress block $(\mathrm{mm}), f_{f}$ is the stress in the FRP bar in tension $(\mathrm{MPa}), f_{f u}$ is the design tensile strength of the FRP bar (MPa), $E_{f}$ is the design or guaranteed modulus $(\mathrm{MPa}), \varepsilon_{c u}$ is the ultimate strain in concrete $(0.003)$, $\beta_{1}$ is an empirical factor, $f_{c}^{\prime}$ is the specified compressive strength of concrete $(\mathrm{MPa}), \rho_{f}$ is the FRP reinforcement ratio, 


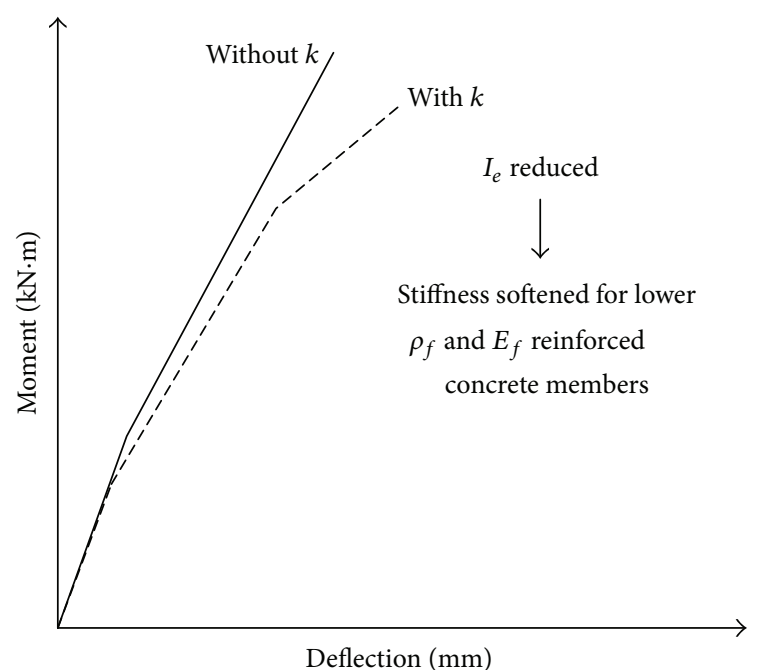

FIGURE 4: Basic concept of considering parameter $k$.

and $\rho_{f b}$ is the balanced FRP reinforcement ratio as given by ACI Committee 440 [2].

\section{Comparative Study for the Prediction of Deflection Behavior Using the Proposed and Existing Models for Calculating the Effective Moment of Inertia}

In this paper, a semiempirical prediction model for the effective moment of inertia is proposed. The model is based on Branson's equation and the modification methodology followed the empirical approach of Toutanji and Saafi [9]. As shown in Figure 4, deflection of the R/C beam with GFRP bars was affected by the reinforcement ratio of GFRP bars as well as the elastic modulus of the GFRP bar. A notable parameter, $K$, to reflect the nonlinear behavior of the $\mathrm{R} / \mathrm{C}$ beams with GFRP bar, is considered empirically to provide good agreement with the experimental tests in this study (see (11)). This factor was used to reduce the effect of the cracked moment of inertia for the reinforced concrete member by including a lower reinforcement ratio and modulus of elasticity for GFRP bar. This considering parameter is the curve fitting factor. Its concept was empirically derived by investigating the results of moment-deflection relationship from the considering equation commented on above in this study. In Figure 6, the considering equations showed the stiff curve as a bilinear behavior up to failure of the test specimen. However, the test result exhibited a nonlinear behavior up to failure so that it can be estimated that a reducing factor should be needed for the good curve fitting to the experimental results. It resulted in a decrease in the effective moment of inertia so that the calculated deflection was increased according to the increase in applied loading. Figure 4 illustrates the basic concept of considering $K$ in the proposed model. Using $K$, the stiffness of the deflection behavior can be softened slightly. This analytical concept may be more appropriate for a concrete member reinforced with

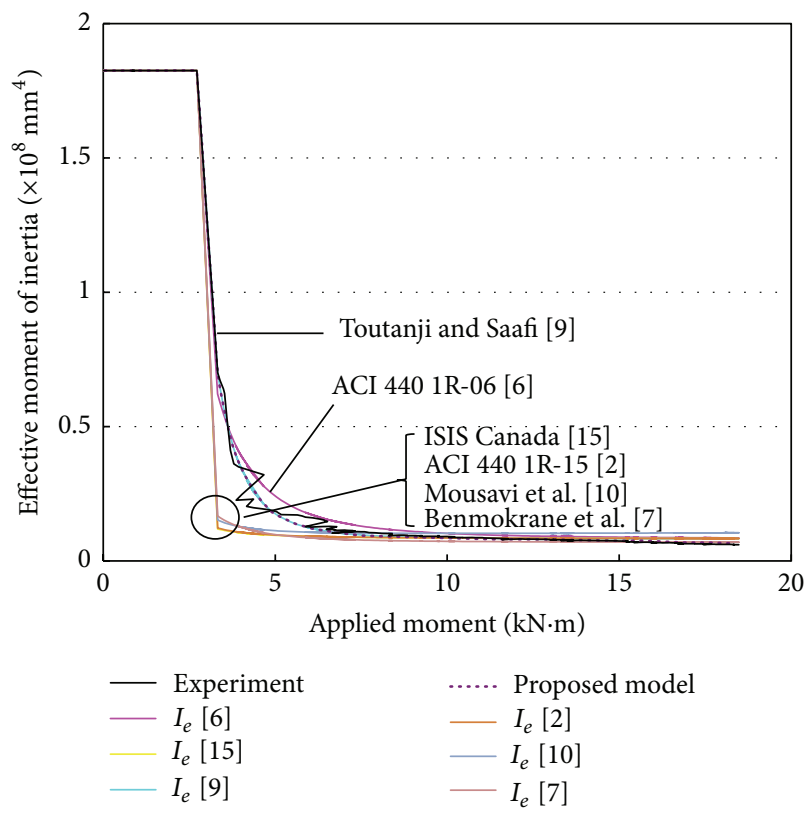

FIGURE 5: Effective moment of inertia of FB-1.

a material with a lower reinforcement ratio and modulus of elasticity:

$$
I_{e}=\left(\frac{M_{\mathrm{cr}}}{M_{a}}\right)^{m} I_{g}+\left[1-\left(\frac{M_{\mathrm{cr}}}{M_{a}}\right)^{m}-K\right] I_{\mathrm{cr}} \leq I_{g}
$$

where $m=6-13 \rho_{\mathrm{F}} E_{\mathrm{F}} / E_{s}$ and $K$ is a nonlinear parameter $\left(=1 / 11\left(M_{\mathrm{cr}} / M_{a}\right)\right)^{4}$.

In total, six codes and developed equations were investigated for a comparative study of the moment of inertia and load deflection according to the experimental tests and the model proposed in this study. For this, a representative specimen for each reinforcing group was considered for the comparison study because of their similarity of the tested results. There are some studies showing that the evaluation of structural capacity of FRP bar-reinforced concrete beam using only one representative specimen for each reinforcing group was successfully done $[14,15]$. Figure 5 shows the results of the comparative study on the effective moment of inertia. There is a noticeable discrepancy between the experiment and equation approaching an applied moment of $5 \mathrm{kN} \cdot \mathrm{m}$. ACI 440 Committee [6], Toutanji and Saafi [9], and the proposed model showed better agreement with good nonlinear prediction of the experimentally obtained effective moment of inertia after the cracking of the concrete. The other equations, such as those of ACI Committee 440 [2], ISIS Canada [12], Mousavi et al. [10], and Benmokrane et al. [7], showed large drops in the gross moment of inertia $\left(I_{g}\right)$ after the cracking of the concrete. They did not represent the hardening behavior of the experimental results well. Two of the prediction models modified from Branson's equation showed good agreement with the experimental results, while the other two models with modified Branson equations showed relatively larger discrepancies. This was caused by 


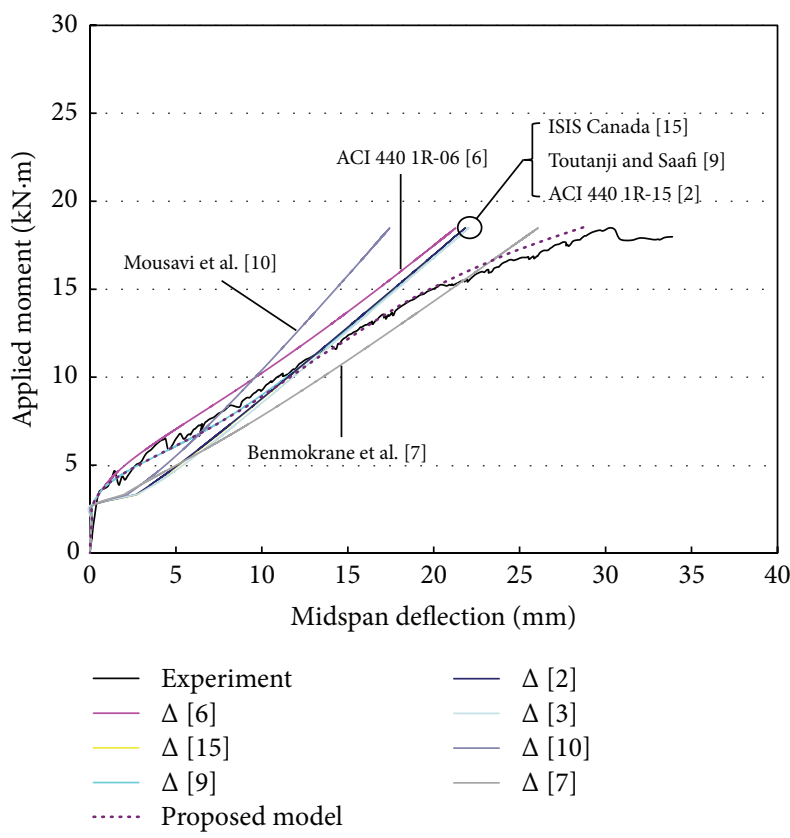

Figure 6: Moment-midspan deflection of FB-1.

application of the empirical parameters, such as the power of $m$ or the multiplying constants.

Figure 6 shows the moment and midspan deflection curve for the FB-1 specimen, which consisted of two R/C beams with GFRP bar. Except for Toutanji and Saafi [9], ACI 440 Committee [6], and Benmokrane et al. [7] equations, plasticity behavior was detected after cracking. These equations underestimated the cracking behavior of the FB-1 specimen, while the experimental results showed hardening behavior with the applied moment. The equation of Mousavi et al. [10] showed the highest stiffness in predicting the deflection. They used almost-identical multiplying constant for the gross and cracked moments of inertia; however, the power of $m$ was different from that of Benmokrane et al. [7]. This difference might make the flexural stiffness in the prediction of deflection more relaxed than that of Benmokrane et al. [7].

ACI 440 Committee [6] and Toutanji and Saafi [9] showed good accordance in deflection behavior until around half of the applied moment; however, after the loading stage, these models behaved as a linear-dependent prediction of deflection. Thus, the difference in the prediction of deflection was increased until the ultimate moment. For the proposed equation, with a nonlinear parameter $K$, it was found that it best predicted the deflection behavior in the experimental test until failure. In Figures 7-10, the analytical effective moment of inertia-applied moment strength and momentdeflection curves obtained from the six equations and the proposed model are compared with the experimental results for FB-2 and FB-3 specimens. The trends in the prediction of deflection were similar to that of the FB-1 specimen, where the ACI 440 Committee [6], Toutanji and Saafi [9], and the proposed models still showed better agreement, with good nonlinear predictions of the experimentally obtained

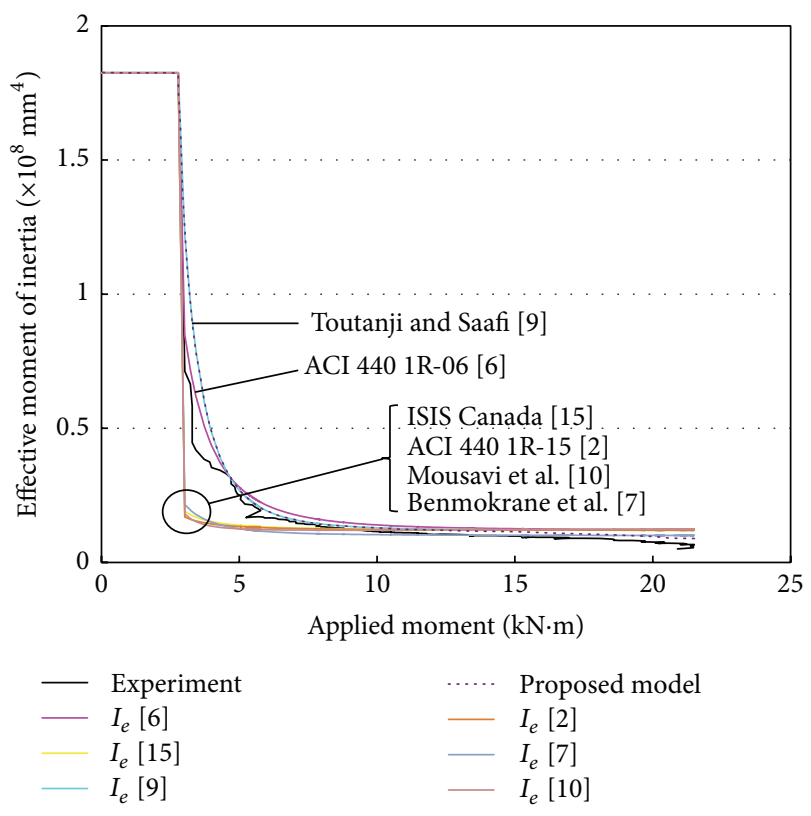

Figure 7: Moment-midspan deflection of FB-2.

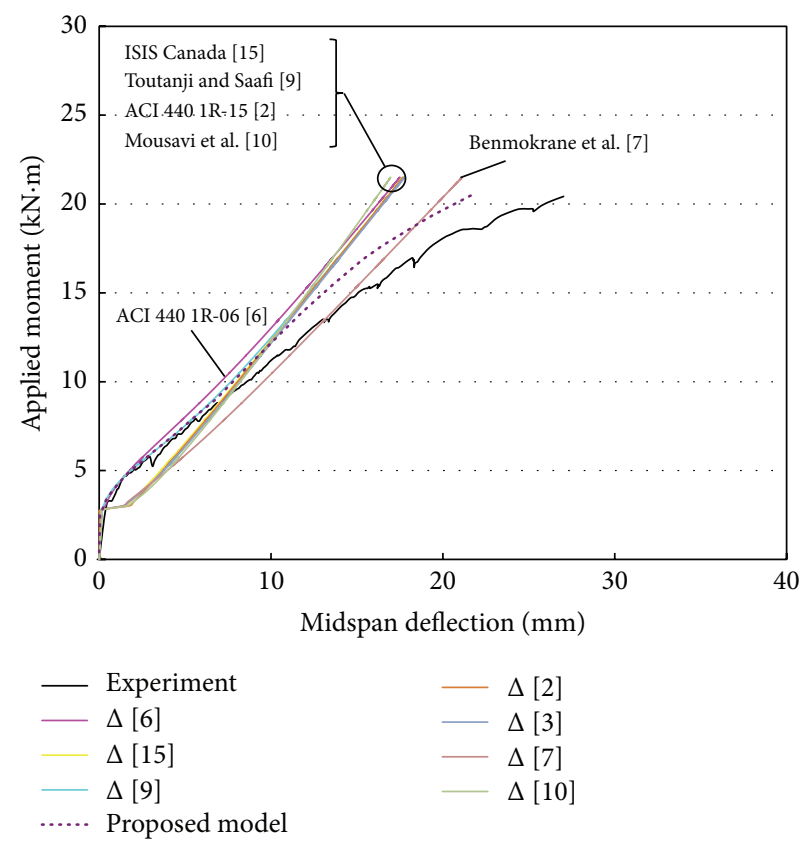

Figure 8: Moment-midspan deflection of FB-2.

effective moment of inertia after cracking of the concrete. The experimental moment-deflection curves of FB-2 and FB3 did not show good agreement with the analytical curves derived from the six equations considered herein but are in good agreement with the proposed model.

The six equations evaluated the moment-deflection response, which was linear compared with the actual response of the test specimens after cracking until ultimate strength is reached. Unlike the ACI 440.1R-06 [6], Toutanji and Saafi [9], and the proposed model, the other equations 

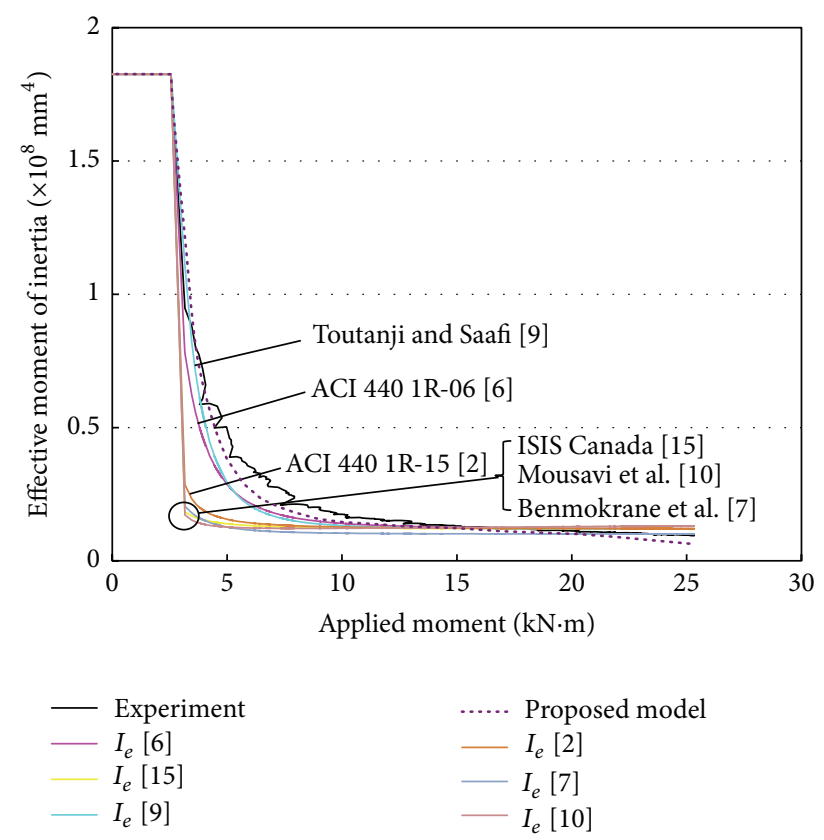

Figure 9: Moment-midspan deflection of FB-3.

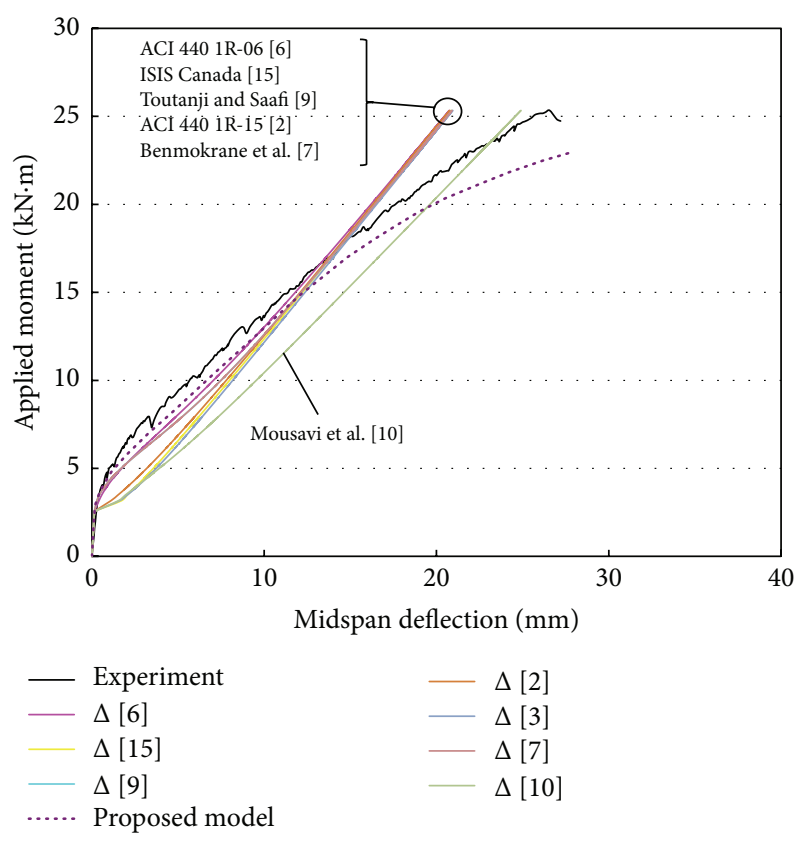

Figure 10: Moment-midspan deflection of FB-3.

did not represent the tension-stiffening effect of the test specimens until around half of the ultimate strength. The reason may be that the equations evaluate the effective moment inertia to be much less than that of the test specimen until the loading stage, and then they respond with a linearly hardening prediction until ultimate strength. The proposed model, however, represented the momentdeflection response well, even the nonlinear behavior, until ultimate strength.

\section{Comparative Study for Validation of the Proposed Model}

To evaluate the generality of the proposed model, some of the previous test results were considered: specimen $\mathrm{Al}$ from Aiello and Ombres [16], specimen BC2HA from Thériault and Benmokrane [17], specimen F1 from Pecce et al. [18], specimen Series 1 from Benmokrane et al. [7], and specimen Group 2 from Al-Salloum et al. [19]. Furthermore, the tested specimens, FB-1, FB-2, and FB-3, from this study were also compared according to the order of the calculated value of equivalent reinforcement ratio with the modulus ratio, $\rho_{\mathrm{F}} E_{\mathrm{F}} / E_{s} . \rho_{\mathrm{F}} E_{\mathrm{F}} / E_{s}$ normalized the reinforcement ratio of the FRP bar to steel bar properties and must be an important index to investigate the validation of momentdeflection behavior with the proposed model. The application criteria of $\rho_{\mathrm{F}} E_{\mathrm{F}} / E_{s}$ can be determined to evaluate the structural behavior of concrete beams reinforced with various reinforcement ratios. Figure 11 shows the results of the comparative study using the proposed model. The results showed that the proposed model reasonably described the moment-deflection behavior of the considered test specimens when $\rho_{\mathrm{F}} E_{\mathrm{F}} / E_{s}$ was varied from 0.00068 to 0.006 . However, the proposed model showed overestimation as $\rho_{\mathrm{F}} E_{\mathrm{F}} / E_{s}$ was increased, for example, to 0.006 for Group 2, so that the application boundary should be investigated further. The FB series showed relatively good agreement with the experimental tests due to the reference specimens used in this study.

For the other specimens, the ascending trend was described well with the experimental results and some discrepancies were detected after cracks occurred. There are some influencing parameters such as concrete property, size effect, and bar type for bonding property. In particular, the bond performance of FRP bar in concrete beam may be more affected by flexural loads than uniaxial tensile load due to its different surface treatment including chemical adhesion property. Further accurate analysis about this should be discussed by experimental and analytical study.

\section{Conclusions}

In this study, we carried out experimental and analytical research to evaluate the flexural capacity and the momentdeflection relationship of concrete beams reinforced with GFRP bars. The proposed model suggested for the effective moment of inertia of R/C beams with GFRP bar could reasonably describe the moment-deflection relationship. The conclusions drawn are as follows:

(i) This study suggested a new equation for the effective moment of inertia for concrete beams reinforced by GFRP bars. The new equation was modified from Branson's equation, which has long been used in this field by structural engineers. The power of $m$ was modified based on Toutanji and Saafi's [9] equation and the nonlinear parameter $K$ was also introduced. This factor was used to reduce the effect of the cracked moment of inertia for the concrete member reinforced with a lower reinforcement ratio 


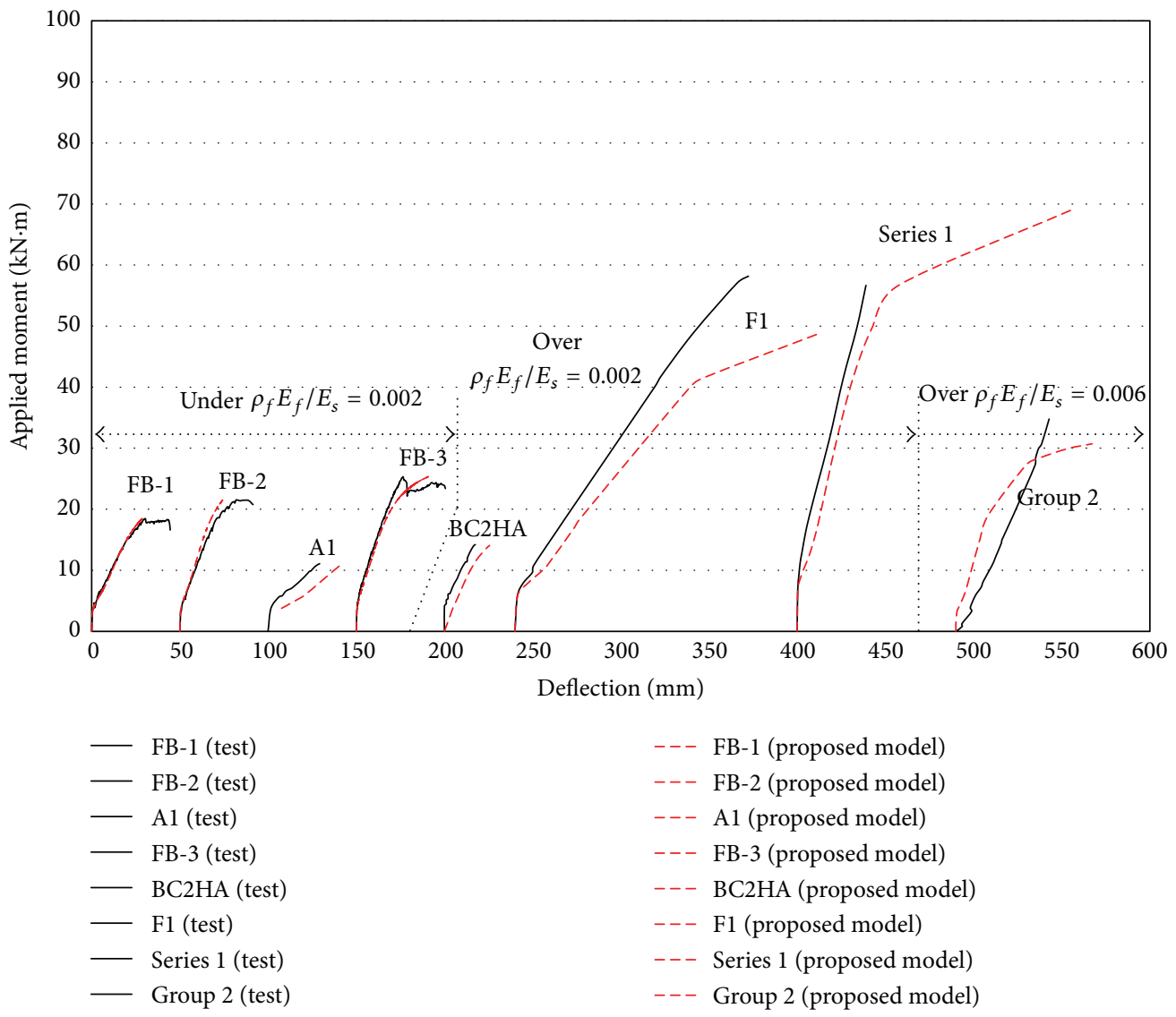

FIGURE 11: Comparison results between experimental tests and the proposed model.

and a material with a lower modulus of elasticity. For comparison with experimental tests, three types of R/C beams with GFRP bar were designed and tested. The predictability of the proposed model was evaluated.

(ii) The comparative study used six equations and the proposed model to calculate the effective moment of inertia and applied moment relationship and found that the equations of ACI 440.1R-06 [6], Toutanji and Saafi [9], and the proposed models showed better agreement with the experimental results. The other three equations considerably underestimated the moment of inertia immediately after concrete cracking. From this result, it was confirmed that the empirical modification based on Branson's equation was valid for predicting the effective moment of inertia and applied moment of the R/C beams with GFRP bar.

(iii) For the prediction of deflection in the experimental tests, the proposed model showed the best predictability among the equations considered. The new model showed better agreement with the deflection behavior of the GFRP bar-reinforced concrete beam until ultimate strength, even with respect to the nonlinear behavior. To evaluate the generality of the proposed model, a comparative study using previous test results, as well as the results from this study, was carried out regarding the moment-deflection relationship. For further study, with regard to the difference in bonding properties of FRP bars, the proposed model could reasonably describe the momentdeflection relationship for the test results considered from previous research and the test results in this study.

(iv) This study confirmed the predictability of the proposed model for the effective moment of inertia. It was found that the modification methodology with an empirical approach was applicable. In terms of future research, it is important that a comparative study with varying reinforcement ratios, bonding properties of FRP bars, and size effects of concrete beams is conducted.

\section{Competing Interests}

The authors declare that they have no competing interests.

\section{Acknowledgments}

This work was supported by a grant (2015R1A2A2A01005286) from the National Research Foundation of Korea (NRF) and a grant (16CTAP-C117247-01) by the R\&D Program from the 
Ministry of Land, Infrastructure and Transport of the Korean Government.

\section{References}

[1] AASHTO, LRFD Bridge Design Guide Specifications for GFRPReinforced Concrete Bridge Decks and Traffic Railings, American Association of State Highway and Transportation Officials, Washington, DC, USA, 2009.

[2] ACI Committee 440, Guide for the Design and Construction of Concrete Reinforced with FRP Bars (ACI 440.1R-15), American Concrete Institute, Farmington Hills, Mich, USA, 2015.

[3] CAN/CSA S806-12, Design and Construction of Building Structures with Fibre-reinforced Polymers, Canadian Standards Association/National Standard of Canada, Ontario, Canada, 2012.

[4] ACI 318, "Building code requirements for structural concrete and commentary," ACI 318-14, American Concrete Institute, Farmington Hills, Mich, USA, 2014.

[5] D. E. Branson, "Instantaneous and time-dependent deflections of simple and continuous reinforced concrete beams," HPR Report no. 7, part 1, Alabama Highway Department, Bureau of Public Roads, Alabama, 1965.

[6] ACI Committee 440, Guide for the Design and Construction of Concrete Reinforced with FRP Bars (ACI 440.1R-06), American Concrete Institute, Farmington Hills, Mich, USA, 2006.

[7] B. Benmokrane, O. Chaallal, and R. Masmoudi, "Flexural response of concrete beams reinforced with FRP reinforcing bars," ACI Structural Journal, vol. 93, no. 1, pp. 46-55, 1996.

[8] M. Ju and H. Oh, "Experimental assessment on the flexural bonding performance of concrete beam with GFRP reinforcing bar under repeated loading," International Journal of Polymer Science, vol. 2015, Article ID 367528, 11 pages, 2015.

[9] H. A. Toutanji and M. Saafi, "Flexural behavior of concrete beams reinforced with glass fiber-reinforced polymer (GFRP) bars," ACI Structural Journal, vol. 97, no. 5, pp. 712-719, 2000.

[10] S. R. Mousavi, M. R. Esfahani, and M. Arabi, "An equation for the effective moment of inertia for FRP-reinforced concrete beams," in Proceedings of the CICE, Rome, Italy, 2012.

[11] P. H. Bischoff, "Reevaluation of deflection prediction for concrete beams reinforced with steel and fiber reinforced polymer bars," Journal of Structural Engineering, vol. 131, no. 5, pp. 752762, 2005.

[12] ISIS Canada, Reinforced Concrete Structures with Fibre Reinforced Polymers Design Manual No. 3, vol. 3, ISIS Canada, Manitoba, Canada, 2007.

[13] ACI Committee 440, "Guide test methods for fiber-reinforced polymers (FRPs) for reinforcing or strengthening concrete structures," ACI 440.3R-04, American Concrete Institute, Farmington Hills, Mich, USA, 2004.

[14] C. Barris, L. I. Torres, A. Turon, M. Baena, and A. Catalan, "An experimental study of the flexural behaviour of GFRP RC beams and comparison with prediction models," Composite Structures, vol. 91, no. 3, pp. 286-295, 2009.

[15] M. Noël and K. Soudki, "Estimation of the crack width and deformation of FRP-reinforced concrete flexural members with and without transverse shear reinforcement," Engineering Structures, vol. 59, pp. 393-398, 2014.

[16] M. A. Aiello and L. Ombres, "Load-deflection analysis of FRP reinforced concrete flexural members," Journal of Composites for Construction, vol. 4, no. 4, pp. 164-170, 2000.
[17] M. Thériault and B. Benmokrane, "Effects of FRP reinforcement ratio and concrete strength on flexural behavior of concrete beams," Journal of Composites for Construction, vol. 2, no. 1, pp. 7-16, 1998.

[18] M. Pecce, G. Manfredi, and E. Cosenza, "Experimental response and code models of GFRP RC beams in bending," Journal of Composites for Construction, vol. 4, no. 4, pp. 182-190, 2000.

[19] Y. A. Al-Salloum, S. H. Alsayed, and T. H. Almusallam, "Evaluation of service load deflection for beam reinforced by GFRP bars," in Proceedings of the 2nd International Conference on Advanced Composite Materials in Bridges and Structures (ACMBS-II '96), pp. 165-172, Montreal, Canada, 1996. 

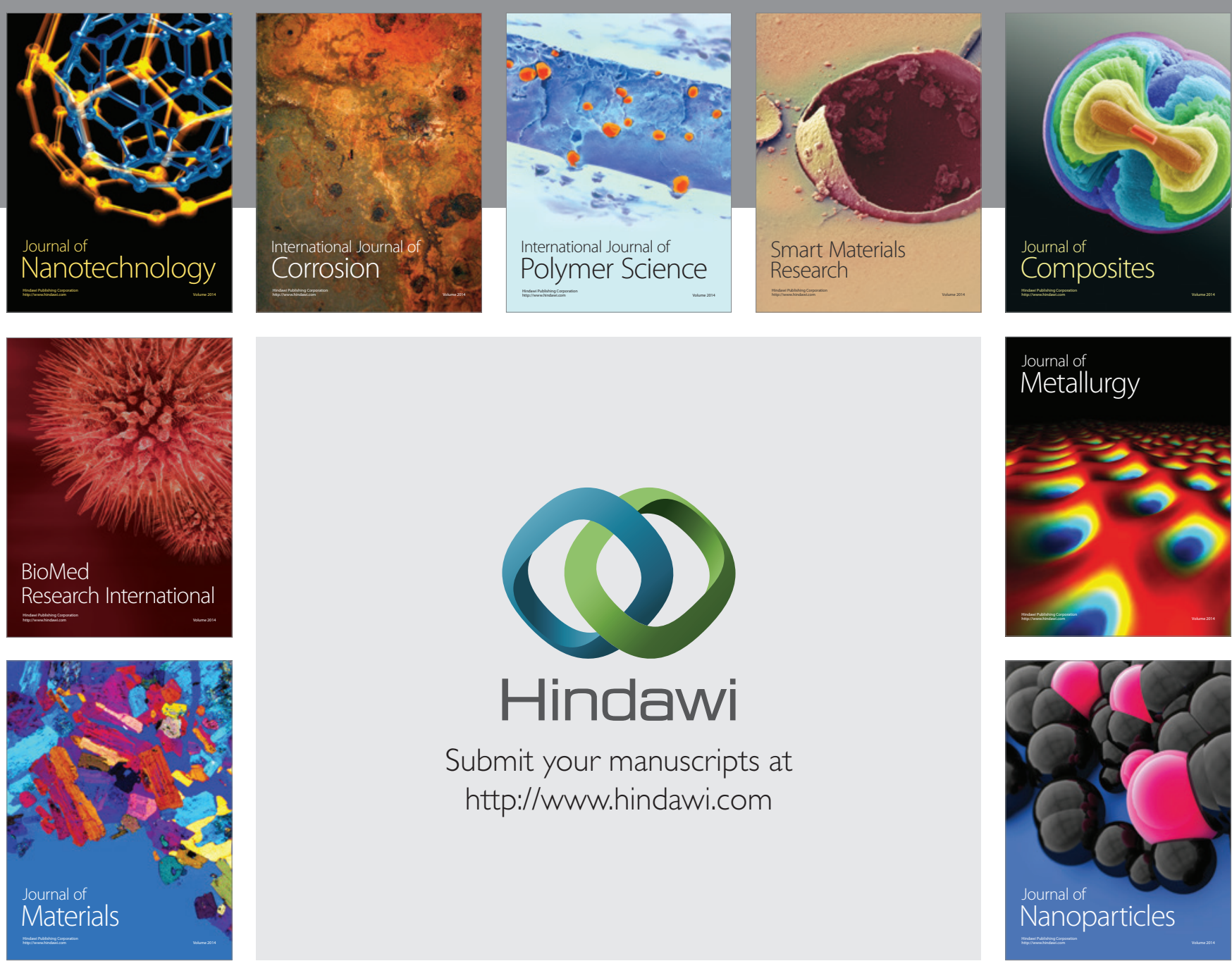

\section{Hindawi}

Submit your manuscripts at

http://www.hindawi.com

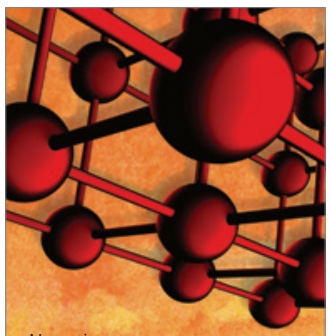

Materials Science and Engineering
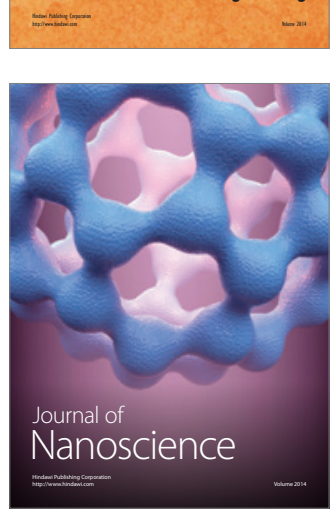
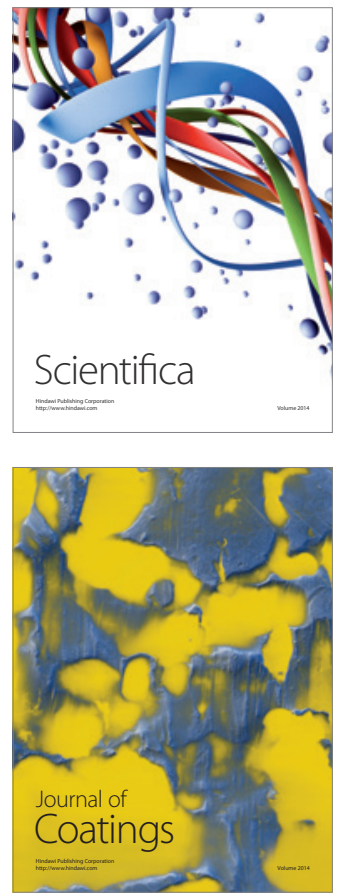
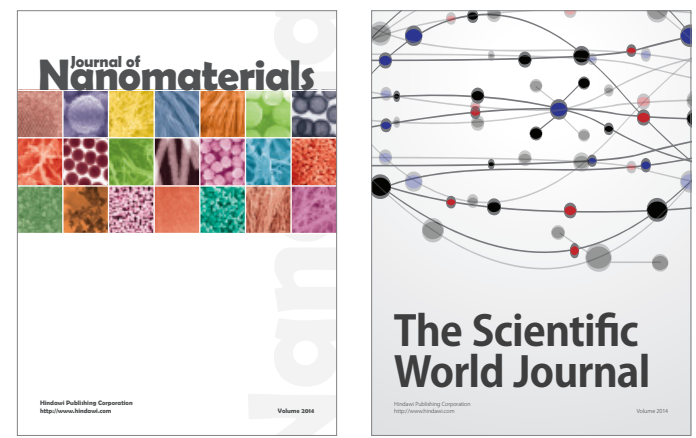

The Scientific World Journal
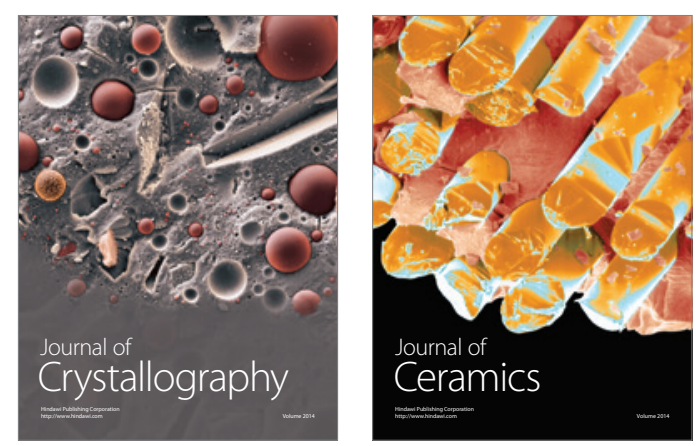
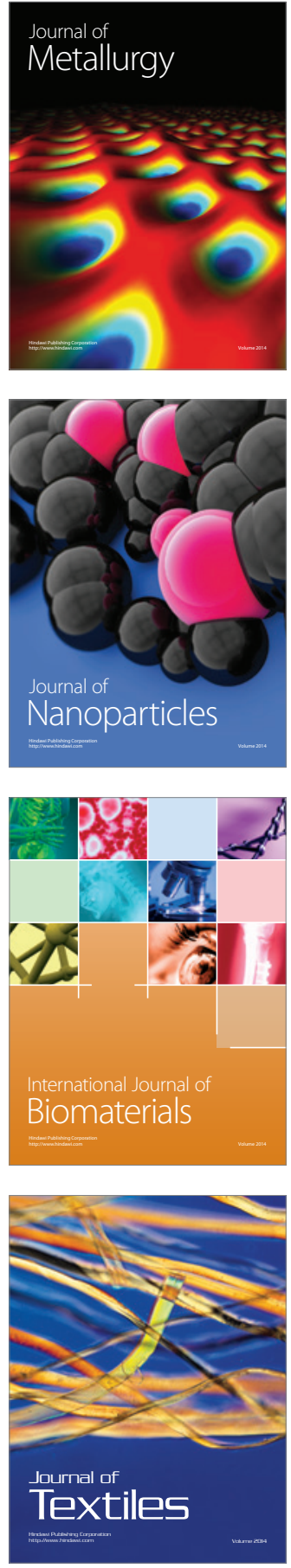